Article

\title{
Growing the Rhinophorid Tree: Three New Species and Their Phylogenetic Implications (Diptera: Rhinophoridae)
}

\author{
Silvia Gisondi ${ }^{1,2}\left(\right.$, Thomas Pape ${ }^{2}\left(\mathbb{D}\right.$, Hiroshi Shima $^{3}$ and Pierfilippo Cerretti ${ }^{1, *(1)}$ \\ 1 Dipartimento di Biologia e Biotecnologie “Charles Darwin”, Sapienza Università di Roma, \\ Piazzale A. Moro 5, 00185 Rome, Italy; silvia.gisondi@uniroma1.it \\ 2 Natural History Museum of Denmark, Universitetsparken 15, 2100 Copenhagen, Denmark; \\ tpape@snm.ku.dk \\ 3 Kyushu University Museum, Kyushu University, Hakozaki, Fukuoka 812-8581, Japan; shimarcb@kyudai.jp \\ * Correspondence: pierfilippo.cerretti@uniroma1.it
}

Zoo Bank: http://www.zoobank.org/AD7C7599-F2A3-4E82-A540-843D294499A6.

Received: 14 October 2020; Accepted: 6 November 2020; Published: 12 November 2020

Simple Summary: Rhinophoridae is a family of oestroid flies which was once considered of strictly Palaearctic distribution. This presupposition has been increasingly contradicted in recent years with the discovery and description of many non-Palaearctic rhinophorid species. In this context, the present research article aims to describe three additional species, namely Aporeomyia elaphocera sp. nov., Baniassa pennata sp. nov. and Phyto mambilla sp. nov., from the Oriental and Afrotropical regions. Their genus-level affiliation is supported by a morphology-based phylogeny and these species are described and illustrated, and a comparison with congeners as well as two identification keys are provided. The phylogeny resulting from the addition of these three new species fits well with previous results but retrieves a paraphyletic Phyto Robineau-Desvoidy. Notwithstanding this, the authors were taxonomically conservative, avoiding the erection of a new genus for a single species as well as the lumping of three different genera into a single one: the evidence for doing either of such actions is considered premature and more data are needed.

Abstract: Three new species of Rhinophoridae (Aporeomyia elaphocera sp. nov., Baniassa pennata sp. nov. from the Oriental Region, and Phyto mambilla sp. nov. from the Afrotropical Region) are described, illustrated and compared with congeners. Genus-level affiliation of the new species is based on a morphology-based phylogeny, preliminarily accepting a paraphyletic Phyto Robineau-Desvoidy awaiting incorporation of molecular data. Keys to the species of the genus Aporeomyia Pape \& Shima as well as to the Afrotropical species of the genus Phyto Robineau-Desvoidy are given.

Keywords: taxonomy; phylogeny; Malaysia; Vietnam; Nigeria; Afrotropical Region; Oriental Region; new species

\section{Introduction}

Rhinophoridae is a small family of oestroid flies, commonly known as woodlouse flies. Their common name is derived from the trophic habit of their larval stage, as these flies are the only insects that evolved parasitism on non-insect pancrustaceans-i.e., the woodlice (Isopoda: Oniscidea) [1-6].

In recent years, research projects concerning rhinophorids have been flourishing, leading to the discovery of several new taxa [7-10] and the publication of a world catalogue with a key to genera [11]. The present paper aims to describe three new rhinophorid species, which are included in ongoing 
molecular studies (Gisondi et al.). Their generic affiliation is argued based on morphology-based phylogenetic analyses.

The description of Aporeomyia elaphocera sp. nov. raises the number of species of the previously monotypic Aporeomyia Pape \& Shima to two, which allows for a generic definition based on synapomorphies. Baniassa pennata sp. nov. is the first species of the genus recorded from the Oriental Region, and it is remarkable by a uniquely shaped distiphallus. Phyto mambilla sp. nov. is the first species of Phyto Robineau-Desvoidy from West Africa; it is characterized by a peculiar color pattern and it is only tentatively assigned to Phyto Robineau-Desvoidy.

\section{Materials and Methods}

Digital images of the external morphology of the holotypes were taken using a Canon EOS 6D camera equipped with Canon Photo lens MP-E 65mm 1.2.8 and processed by Canon Digital Photo Professional (Canon, Ōta, Tokyo, Japan), Combine ZM by Alan Hadley and GIMP 2.10.4 by Alexandre Prokoudine. Terminology of the external morphology, and measurements and ratios of the head follow Cumming and Wood [12] and Cerretti et al. [11], respectively. We follow Cerretti et al. [11] in using the term "global apomorphy" for an uncontradicted and unreversed apomorphic character state, whereas "local apomorphy" is used for a character state that is homoplasious due to convergence or reversal.

Male terminalia were dissected following the method described by $\mathrm{O}^{\prime} \mathrm{Hara}$ [13], and digital images were taken using a DM-LS microscope (Leica, Germany) equipped with a DS-L1 Nikon digital camera (Nikon, Tokyo) and processed using CombineZM (Hadley, UK).

Label data are reported verbatim, with a slash "/" marking the end of each line and a double-slash "/I" marking the end of a label. Abbreviations for depositories reported in this work are as follows:

BLKU: Biosystematics Laboratory, Kyushu University, Fukuoka, Japan.

CSCA: California State Collection of Arthropods, Sacramento, CA, USA.

CNC: Canadian National Collection of Insects, Arachnids, and Nematodes, Ottawa, ON, Canada.

MZUR: Museum of Zoology, "Sapienza" Università di Roma, Rome, Italy.

NHMD: Natural History Museum of Denmark, Copenhagen, Denmark.

For the cladistic analysis, the morphological data matrix from Cerretti et al. [11,14] was updated using the software Mesquite [15] to include the three species described here (Matrix S1). Thus, 71 taxa and 100 morphological characters were analyzed through parsimony analyses performed with the TNT software (v1.6-beta) [16]. Characters were treated as unordered and analyzed under implied weighting with a $k$-value $\geq 4$ using the "traditional search" algorithm under the following settings: general RAM of 1.0 Gbyte, memory set to hold 1,000,000 trees, 1000 replicates with the tree bisection reconnection (TBR) [17] branch swapping algorithm and saving 1000 trees per replicate. $k$-value was chosen both for consistency reasons with Cerretti et al. [11], who obtained the fittest tree with a $k$-value of 4 , but also because low $k$-values $(<3)$ exclude a large amount of information by strongly down weighting homoplasy, whereas larger values $(\geq 3)$ allow for some signal to come from homoplasy [18]. Branches not discussed in the present paper were collapsed. Consistency and retention indices were calculated using the "States.run" script implemented in TNT.

\section{Results}

\subsection{Cladistic Results}

Analyses yielded one fittest tree (Figure 1). The same topology was retrieved for all $k$-values at or above 4 . 


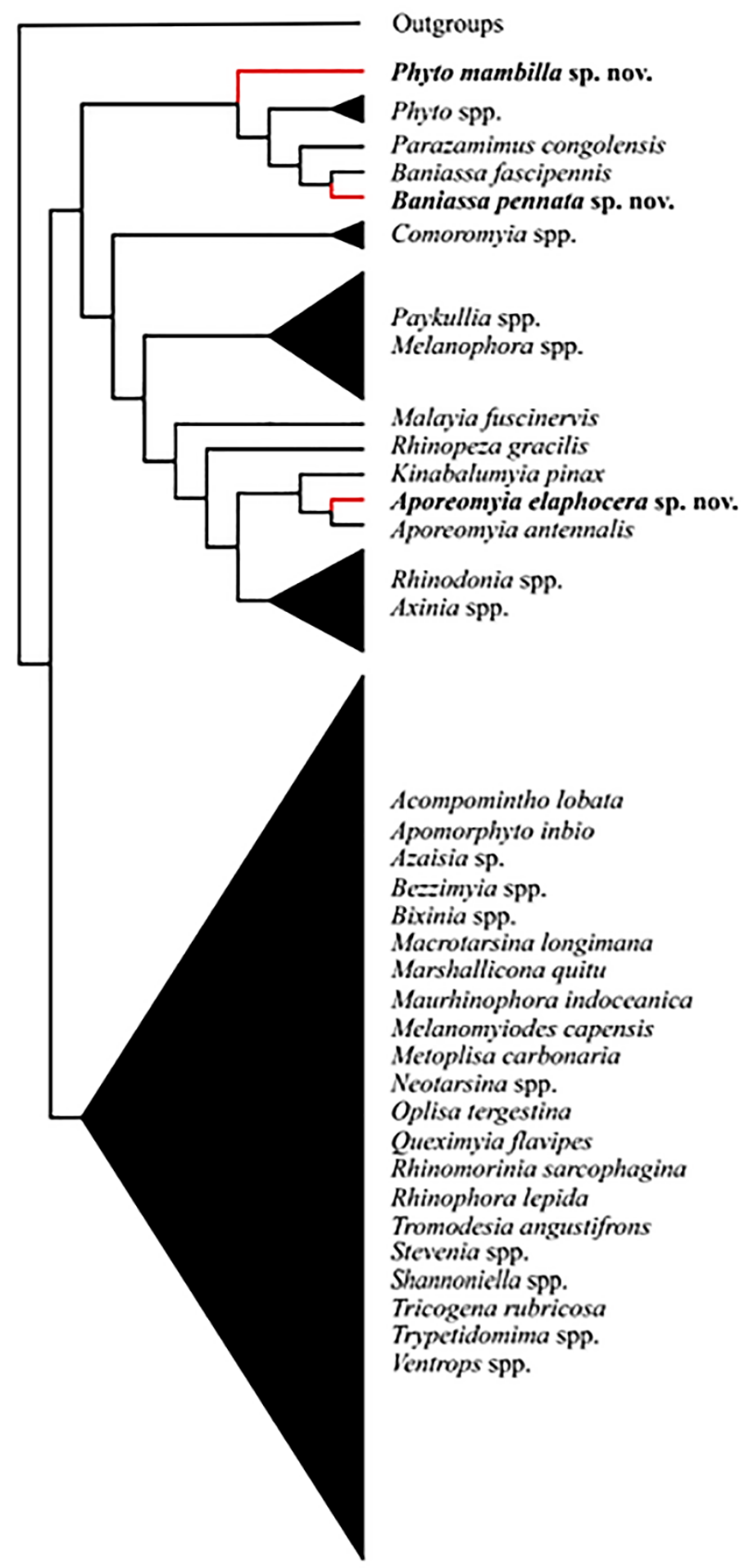

Figure 1. Fittest tree obtained using TNT under implied weighting and a $k$-value $\geq 4$.

Aporeomyia elaphocera sp. nov. clusters with Aporeomyia antennalis Pape \& Shima based on one global apomorphy (male postpedicel branches from the base into three lobes (Matrix S1: 1:1)) and six local apomorphies (male proclinate orbital setae absent; facial plate deeply sunken; mouthparts strongly reduced; transversal section of sternite 5 almost flat; median extension of surstylus with setae; median process of ventral sclerotization of distiphallus absent (Matrix S1: 10:0; 15:1; 21:1; 55:1; 65:1; 75:1)). Aporeomyia Pape \& Shima is retrieved as sister to Kinabalumyia Cerretti \& Pape (see also [11], 
as Aporeomyia sp.), supported by one global apomorphy (first aristomere at least $4 \times$ as long as wide (Matrix S1: 7:2)) and two local apomorphies $(\mathrm{CuA}+\mathrm{CuP}$ reaching wing margin; male tergite 6 fused to syntergosternite $7+8$ (Matrix S1: 51:1;59:1)). Aporeomyia + Kinabalumyia clusters within an Australasian and Oriental clade inside the Phyto-group, based on one local apomorphy (arista thickened at least on basal 3/4 (Matrix S1: 6:1)).

Baniassa pennata sp. nov. clusters with Baniassa fascipennis Kugler based on four local apomorphies (lappets of metathoracic spiracle unequal in size with the posterior one distinctly larger and closing the spiracle like an operculum; female fore tarsus laterally compressed; setae on median extension of surstyli present; median process of ventral sclerotization of distiphallus not connected to ventral plate (Matrix S1: 31:2; 33:1; 65:1; 76:0)).

Phyto mambilla sp. nov. is recovered within a clade consisting of other species of Phyto plus Parazamimus and Baniassa, and it emerges as sister to the remaining part of this clade-i.e., ((Phyto adolescens + P. angustifrons) + (Parazamimus Verbeke [19] + Baniassa Kugler)), based on the lack of setosity in the lower half of the parafacial (Matrix S1: 18:0), thus resulting in a paraphyletic Phyto.

\subsection{Taxonomy}

Aporeomyia Pape \& Shima, 1993.

Aporeomyia Pape \& Shima, 1993: 77 (original description). Type species: Aporeomyia antennalis Pape \& Shima, 1993: 77, by original designation.

References: [11,20].

Diagnosis. Male: Medium-sized, slender flies, with relatively large wing. Head profile narrowed ventrally. Prementum and palpus short. Antenna very large and with postpedicel tripartite from base. Arista inserted on anterior lobe. Prosternum bare. Scutellum slightly swollen. Vein M almost straight and without a bend. Veins $\mathrm{M}_{4}$ and $\mathrm{CuA}+\mathrm{CuP}$ extended to wing margin. Lower calypter narrow and with median margin diverging from scutellum. Hind tibia with posteroventral apical seta.

Apomorphies. Male: postpedicel very large and tripartite nearly from base; proclinate orbital setae absent; facial plate deeply sunken; mouthparts strongly reduced; transversal section of sternite 5 almost flat; median extension of surstylus with setae; median process of ventral sclerotization of distiphallus absent.

Aporeomyia elaphocera sp. nov.

http://www.zoobank.org/A5B08995-E69D-4A5A-B868-AC8655498782 (Figures 2 and 3)

Type material. HOLOTYPE ơ: Malaysia, Sabah. Label data: "Malaysia: Sabah: Crocker/Range, Gunung Emas;/5.847000 N 116.322000 E;/26.x-18.xi.2011; S. Bosuang;/Malaise trap; CNC823099." (CSCA).

Paratypes: $3 \sigma^{7} \sigma^{x}$, with label data: "Malaysia, Sabah (Borneo)/Penampang Distr., Crocker Range/Gunung Emas, 1700 m, 15-25. X. 2011/549'42” N 116 20’00" E, Malaise/M. Hauser \& S. Gaimari leg." (1 CNC, 1 MZUR, 1 NHMD).

Etymology. The specific epithet, which should be treated as a noun in apposition, is derived from the specific epithet for the red deer, Cervus elaphus Linnaeus, and it refers to the morphology of the postpedicel, tripartite and recalling deer antlers.

Diagnosis. Male postpedicel tripartite from base with the three tips running almost straight (not curved as in A. antennalis Pape \& Shima). Base of vein $\mathrm{R}_{4+5}$ bare dorsally. General ground color dark brown (pale brownish in A. antennalis). 


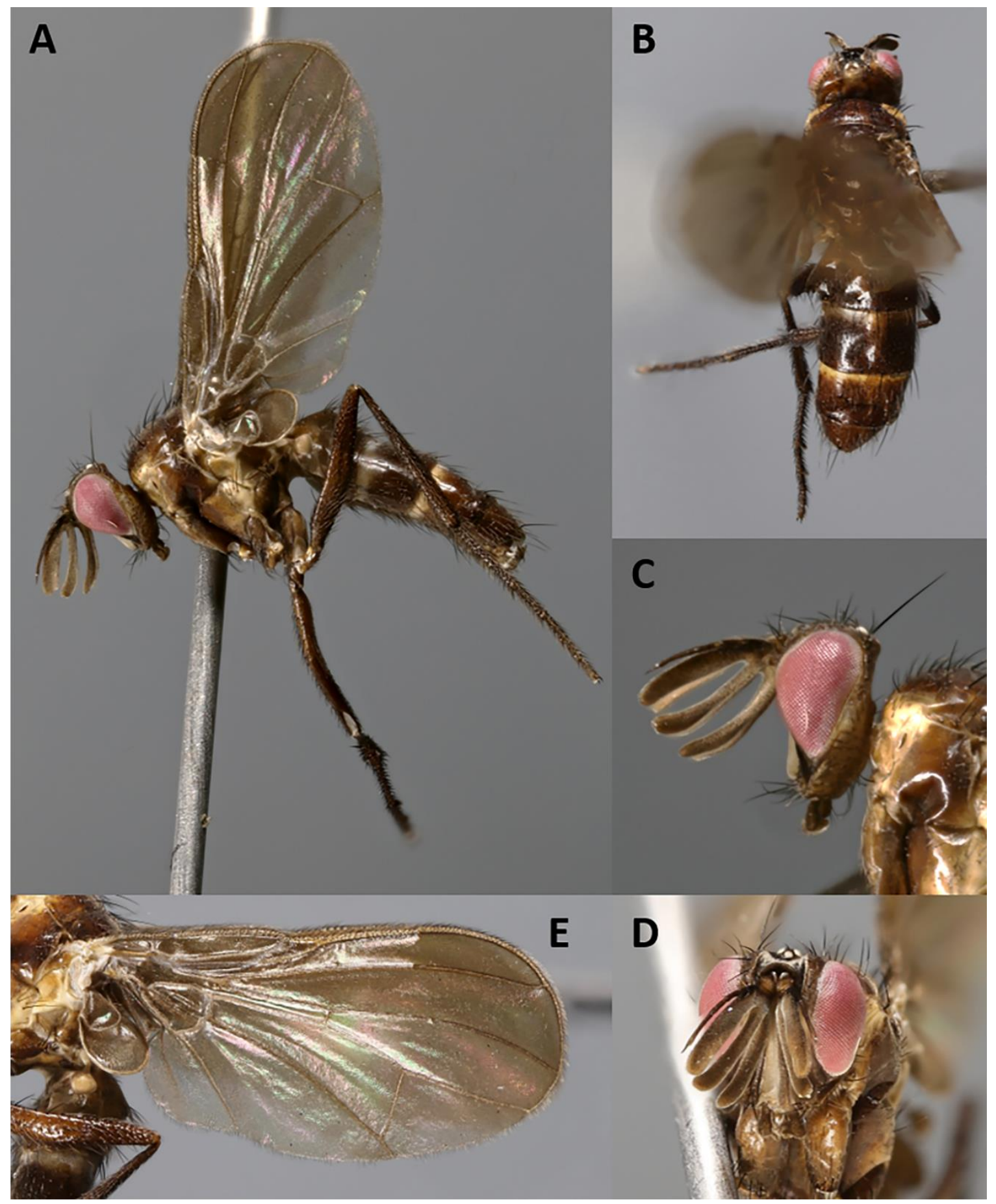

Figure 2. Aporeomyia elaphocera sp. nov. (paratype $\sigma^{7}$, MZUR). (A) Habitus in lateral view; (B) dorsal habitus; (C) head in lateral view; (D) head in frontal view; (E) left wing in ventral view. 
A

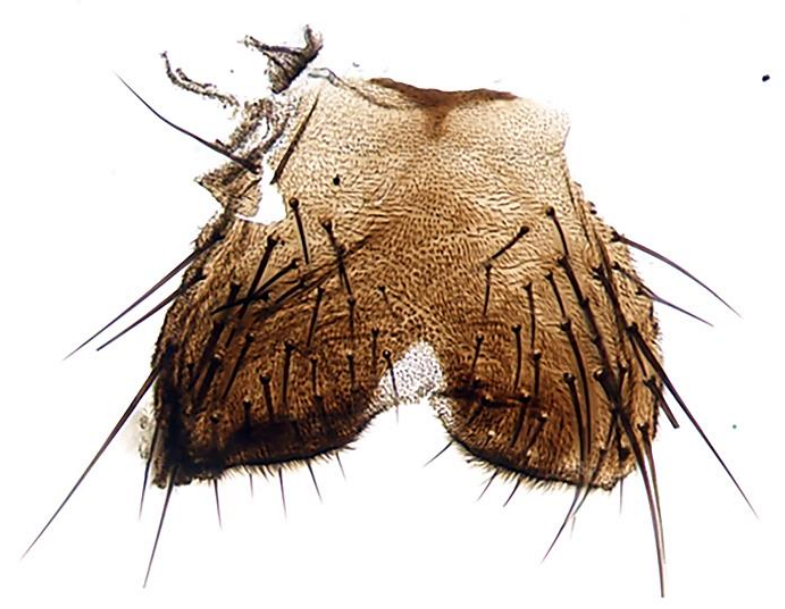

B

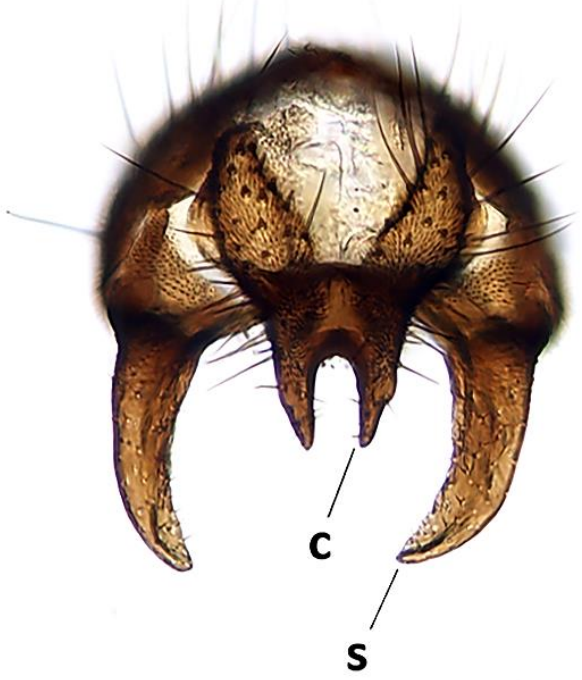

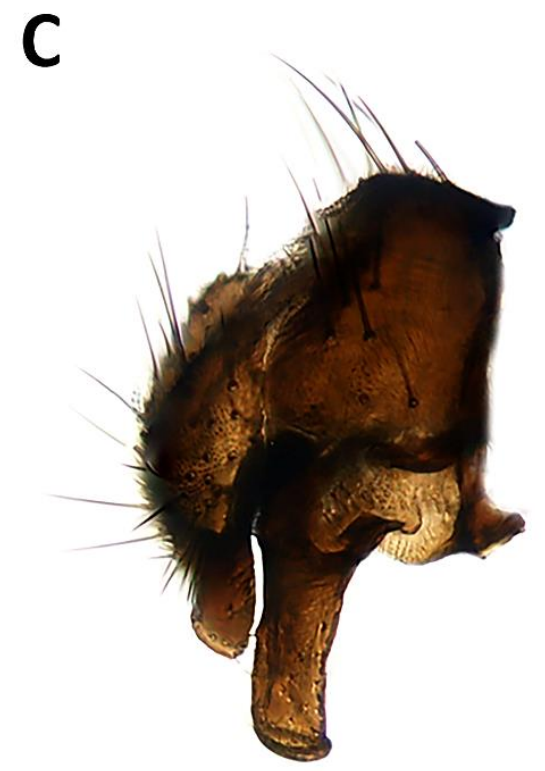

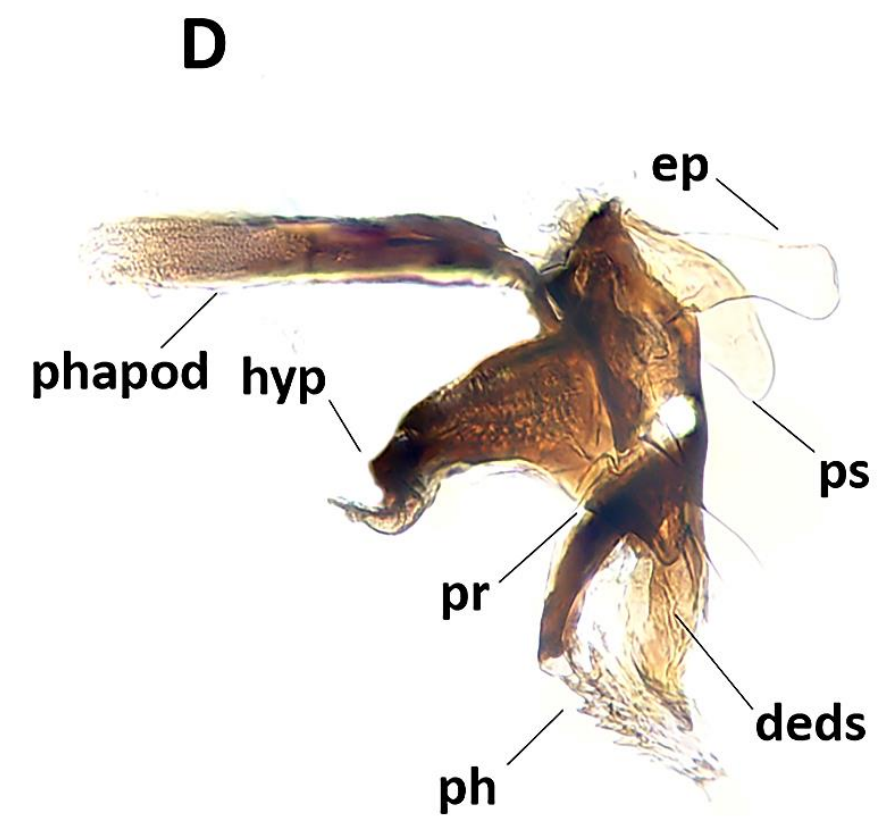

Figure 3. Aporeomyia elaphocera sp. nov., terminalia (holotype $\sigma^{7}$, CSCA). (A) Sternite 5 in ventral view; (B) epandrial complex in posterior view, c = cercus, s = surstylus; (C) epandrial complex in lateral view; (D) hypandrial complex and phallus in lateral view, phapod = phallapodeme, deds = dorsal extension of dorsal sclerite of distiphallus, ep = epiphallus, hyp = hypandrium, $\mathrm{ph}=$ phallus, $\mathrm{pr}=$ pregonite, $\mathrm{ps}$ $=$ postgonite.

Description. Male (Figures 2 and 3).

Length: $4.5-4.7 \mathrm{~mm}$.

Color (Figure 2). Head mostly brown shading into yellowish towards occipital area; frontal vitta black; area between gena and parafacial blackish; scape and pedicel yellowish to light brown; postpedicel and arista blackish-brown; palpus brown. Scutum and scutellum blackish-brown in ground color; scutum covered with barely visible microtomentum except along three thin pre- and postsutural dark vittae (visible in posterodorsal view); postpronotum yellow; thorax in lateral view with two yellow stripes (anterior one descending from postpronotum to fore coxa, across anterior spiracle, proepisternum and proepimeron; posterior one descending from wing base across anterior half of anepimeron and posterior two-thirds of katepisternum), remaining of pleura brown. Legs 
dark brown. Upper and lower calypters and wing membrane slightly smoky; tegula brownish and basicosta yellow; wing veins yellow; halter brownish-yellow. Abdomen mostly dark brown in ground color, with anterior portion of tergites 3 and 4 yellowish; tergites 3 and 4 with band of weak, whitish microtomentum on anterior $1 / 3$ (dorsally); terminalia brown.

Head (Figure 2A-D). Head shape receding, roughly triangular in lateral view (i.e., narrowing toward mouthparts). Frons $2.0 \times$ as wide as compound eye in dorsal view. Inner vertical seta well developed, $0.8 \times$ as long as compound eye height. Outer vertical seta not differentiated. Ocellar triangle with three pairs of short hair-like proclinate setulae (i.e., ocellar seta not differentiated). Frons with 1-4 frontal setae from anterior margin of ocellar triangle and descending at most until middle of pedicel. Fronto-orbital plate with 1 lateroclinate and 3-4 proclinate orbital setae. Upper reclinate orbital setae absent. Parafacial very narrow, as wide as or narrower than width of arista at mid-point. Facial ridge concave with a few fine setulae above vibrissa on lower 1/10 approximately. Vibrissa inserted below level of lower facial margin. Lower facial margin visible in lateral view. Gena approximately 0.3 of compound eye height. Genal dilation weakly developed. Antenna $4 \times$ as long as height of gena. Postpedicel tripartite (three branches approximately of equal length), 1.0-1.2 $\times$ as long as compound eye height. Arista inserted on dorsal branch of postpedicel at 0.15 from base to tip and thickened on nearly whole length. First and second aristomeres elongated, approximately $4-5 \times$ as long as wide, both with a seta dorsally. Prementum and palpus very short, almost vestigial.

Thorax. Postpronotum with two setae (Figure 2A). Acrostichal setae absent. One presutural and two postsutural dorsocentral setae. One presutural and one postsutural intra-alar setae. First postsutural supra-alar seta absent. Two + one katepisternal setae. Katepimeron and anepimeron bare. One pair of apical scutellar setae, crossed; one pair of subapical scutellar setae. Anatergite with tuft of short setulae below scutellum. Anterior and posterior fringes of posterior spiracle equal in size and emerging from spiracular rim. Legs. Preapical anterodorsal seta of fore tibia about as long as preapical dorsal seta. Mid tibia with one anterodorsal seta. Hind tibia with three preapical dorsal setae. Preapical posteroventral seta of hind tibia about as long as preapical anteroventral seta. Hind tibia with one well-developed anterodorsal seta. Posterodorsal margin of hind coxa bare. Wing (Figure 2A,E). Lower calypter tongue-shaped. Second costal section $\left(\mathrm{CS}_{2}\right)$ setulose ventrally. Costal spine not differentiated from other costal setulae. Vein $\mathrm{R}_{1}$ bare. Base of vein $\mathrm{R}_{4+5}$ bare. Vein $\mathrm{M}$ reaching wing margin without bend.

Abdomen (Figure 2A,B). Mid-dorsal depression of syntergite $1+2$ confined to anterior 1/4 of syntergite. Syntergite $1+2$ and tergite 3 with two (one per side) median marginal setae. Tergites 4 and 5 each with row of marginal setae. Tergite 5 short, approximately $0.7 \times$ as long as tergite 4 . Sternite 4 exposed. Terminalia (Figure 3). Sternite 5 with narrow V-shaped posteromedian notch without membranous window; anterior margin of sternite 5 about half as wide as posterior margin (Figure 3A). Transversal section of sternite 5 almost flat. Tergite 6 normally developed (i.e., plate-like) with median marginal setae, and fused to syntergosternite $7+8$. Connection between sternite 6 and syntergosternite $7+8$ membranous on right side. Epandrium short and convex, with very short anterior prolongation and weakly developed posterior lobe. Cerci normally developed, fused medially at base, distally developed in two pointed, finger-like branches. Surstylus normally developed, relatively narrow and curved inward distally; setae on median extension present. Bacilliform sclerite and surstylus articulated (i.e., not fused). Connection between surstylus and epandrium membranous. Hypandrial arms converging medially, not fused. Connection between phallic guide and pregonite membranous (i.e., not fused). Anterior seta on postgonite absent. Extensions of dorsal sclerite of distiphallus relatively short and partly fused medially to dorsal sclerite of basiphallus. Median process of ventral sclerotization of distiphallus absent. Acrophallus simple, unmodified (apparently with one opening).

Female. Unknown

Distribution. Oriental: Malaysia (Sabah).

Biology. Unknown. 
Key to species of Aporeomyia Pape \& Shima

1. Arista inserted on dorsal branch of postpedicel at about 0.3 from base to tip; first aristomere about as long as wide, second aristomere $2-3 \times$ as long as wide. Basicosta dark brown; wing vein $\mathrm{R}_{1}$ setulose dorsally on distal $1 / 2-2 / 3$; vein $\mathrm{R}_{4+5}$ setulose dorsally at base and from approximately junction with $r-m$ almost to wing margin. Legs pale brownish yellow.

Aporeomyia antennalis Pape \& Shima, 1993 (Philippines: Mindanao)

- $\quad$ Arista inserted on dorsal branch of postpedicel at 0.15 from base to tip; both first and second aristomeres elongated, approximately $4-5 \times$ as long as wide. Basicosta yellow; wing vein $\mathrm{R}_{1}$ bare; vein $\mathrm{R}_{4+5}$ bare. Legs dark brown.

Aporeomyia elaphocera sp. nov. (Malaysia: Borneo)

Baniassa Kugler, 1978

Baniassa Kugler, 1978: 73 (original description). Type species: Baniassa fascipennis Kugler, 1978: 74, by original designation.

References: [11,14,21-24].

Diagnosis. Male frons narrow, without proclinate orbital and upper reclinate orbital setae. Lunule with setulae. Parafacial varying from nearly bare to almost entirely setulose. Facial ridge bare or with few decumbent setae on lower third. Palpus well developed. Posterior lappet of metathoracic spiracle distinctly larger than anterior lappet. Vein $\mathrm{R}_{1}$ bare. Vein $\mathrm{R}_{4+5}$ with a few short setulae confined at base or bare. Cell $r_{4+5}$ open or petiolate. Female fore tarsus laterally compressed. Male: Median process of ventral sclerotization of distiphallus interrupted proximally and not connected to ventral plate; surstylus with setae on medial plate.

Apomorphies. Posterior lappet of metathoracic spiracle distinctly larger than anterior lappet. Male: Median process of ventral sclerotization of distiphallus interrupted proximally and not connected to ventral plate; surstylus with setae on medial plate. Female: fore tarsus laterally compressed.

Baniassa pennata sp. nov.

http://www.zoobank.org/73D656F3-8F51-4427-871A-850223095F36 (Figures 4-7).

Type material. HOLOTYPE ơ: Vietnam, Cao Bang Province. Label data: “Vietnam: Cao Bang/ Prov., Mt. Pia Oac/1320 m/23-27.v.1999/Col. H. Kurahashi." (BLKU).

PARATYPES: $3 \sigma^{7} \sigma^{7}$, same data as holotype (1 BLKU, 1 MZUR, 1 NHMD); 2 + , 1 \%, same data as holotype (BLKU), 1 \%, with label data: "Vietnam: Ninh Binh/Prov. Cuc Phuong Natl. /Park, 24-28.iii.2012/20²1'03" N 105³5’36" E/SD Gaimari, M Hauser, /HT Pham 390 m." (CSCA).

Etymology. The specific epithet, which should be treated as a Latin adjective, is derived from the Latin "pennatus" meaning "feathered", and it refers to the long, feather-like sclerotizations characterizing the lateral lobes of the distiphallus.

Diagnosis. Parafacial bare in ventral half. Postpronotum with three setae. First postsutural supra-alar seta strong, distinctly longer and thicker than notopleural seta. Bend of vein $\mathrm{M}$ not reaching vein $R_{4+5}$ so that cell $r_{4+5}$ is open at wing margin. Bacilliform sclerite firmly fused to surstylus. Female thorax ground color black. 


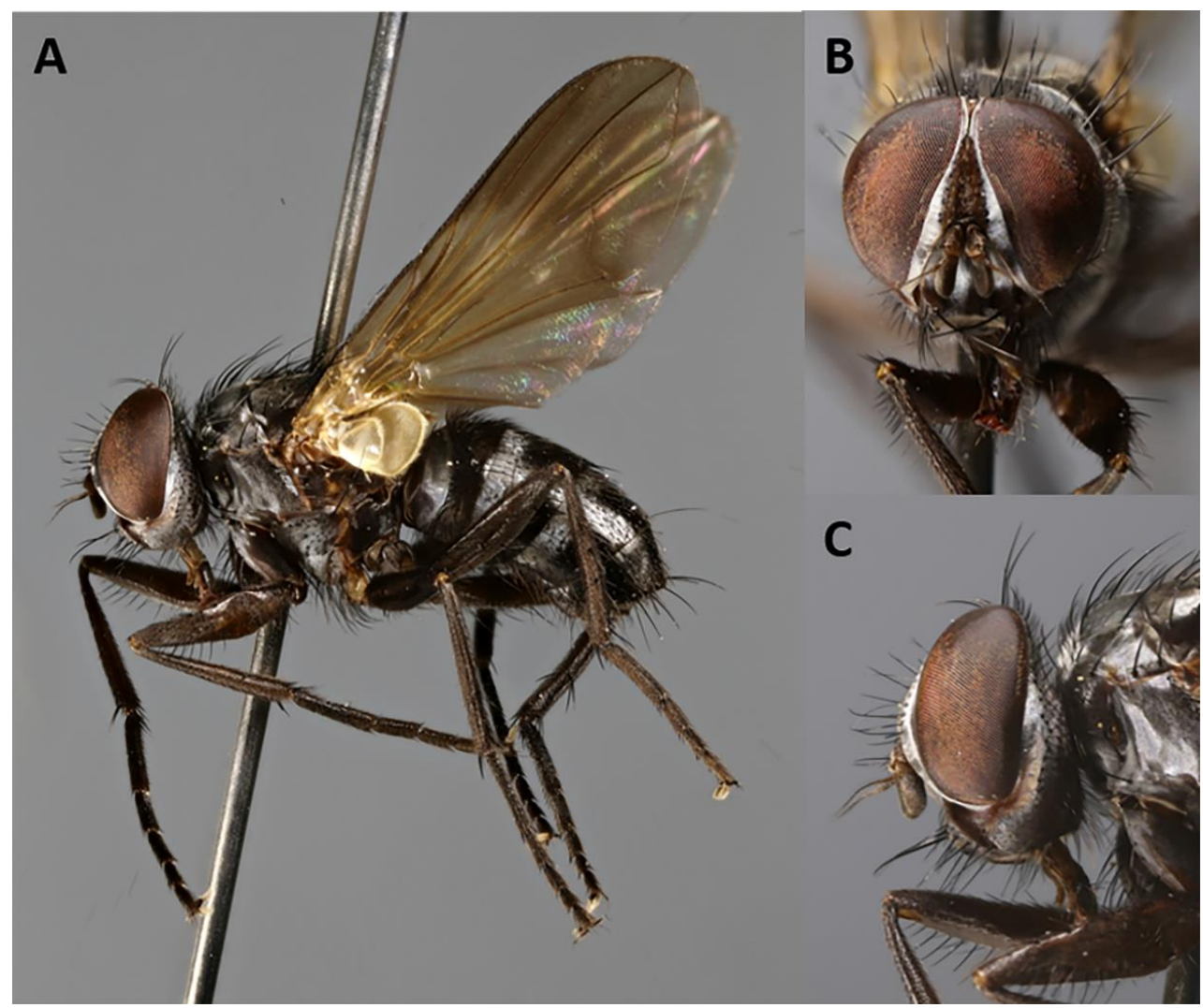

Figure 4. Baniassa pennata sp. nov. (holotype $\sigma^{7}$, BLKU). (A) Habitus in lateral view; (B) head in frontal view; (C) head in lateral view.

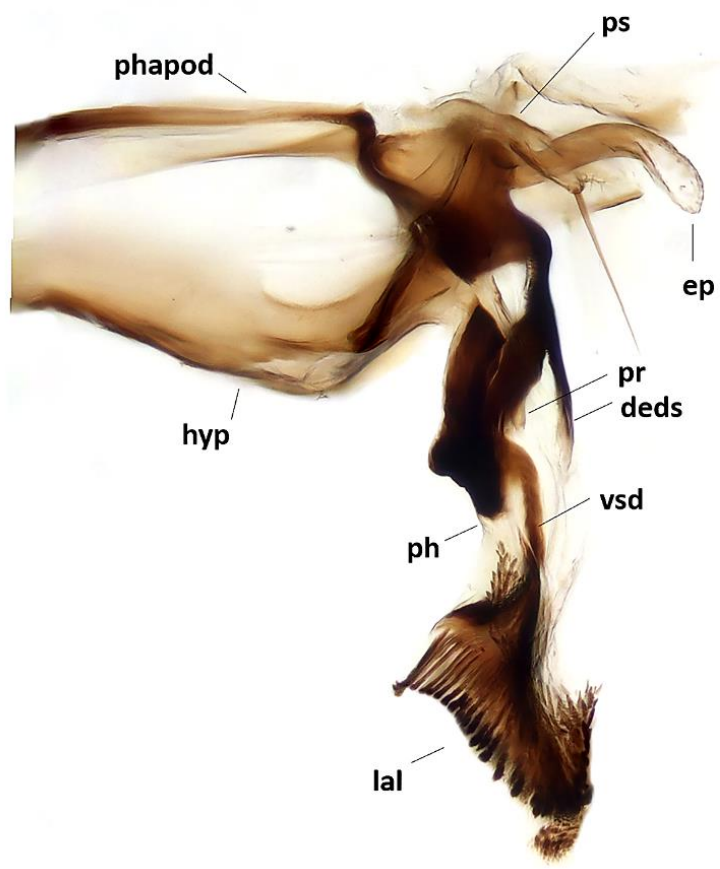

Figure 5. Baniassa pennata sp. nov., male terminalia (holotype $\sigma^{\prime \prime}$, BLKU): hypandrial complex in lateral view, phapod $=$ phallapodeme deds $=$ dorsal extension of dorsal sclerite of distiphallus, ep = epiphallus, hyp = hypandrium, lal = lateral lobes, $\mathrm{ph}=$ phallus, $\mathrm{pr}=$ tip of pregonite, $\mathrm{ps}=$ postgonite, $\mathrm{vsd}=$ ventral sclerotization of distiphallus. 
Description. Male (Figures 4 and 5).

Length: $4.2-4.9 \mathrm{~mm}$.

Head (Figure $4 \mathrm{~A}-\mathrm{C}$ ). Frons $1 / 4$ of a compound eye in dorsal view. Inner vertical setae well developed, approximately $0.4 \times$ as long as compound eye height. Outer vertical seta not or weakly differentiated from postocular setulae. Ocellar triangle with one pair of proclinate ocellar setae and 3-4 pairs of short hair-like proclinate setulae. Frons with 8-9 frontal setae descending to upper margin of scape. Fronto-orbital plate bare on dorsal 2/3, with minute setulae on distal third, sometimes descending to upper half of parafacial. Upper reclinate orbital setae absent. Proclinate orbital setae absent. Parafacial approximately $0.8-1.1 \times$ as wide as postpedicel at mid length, with $1-7$ short hair-like setulae on upper half. Facial ridge concave with fine setae above vibrissa at most on lower $1 / 5$. Vibrissa inserted at level of lower facial margin. Face and lower facial margin not visible in lateral view. Gena approximately $0.24-0.27$ of compound eye height. Genal dilation well developed. Antenna long, 3/4 of height of gena. Postpedicel 2.0-2.4× as long as pedicel. Arista with minute trichia shorter than its greatest diameter, and thickened on proximal 1/4. First aristomere very short, not longer than wide. Second aristomere slightly larger than first, not longer than wide. Prementum about twice as long as width at mid length. Palpus apically enlarged.

Thorax. Postpronotum with three setae arranged in line of obtuse triangle (Figure 4A). Two presutural and one postsutural acrostichal setae. Two presutural and three postsutural dorsocentral setae. Two postsutural intra-alar setae separated by distance greater than distance between first seta and suture. First postsutural supra-alar seta well developed-i.e., distinctly longer than notopleural setae. Two + one katepisternal setae. Katepimeron with two hair-like setulae. Anepimeral seta short. One pair of apical scutellar setae, crossed. One pair of basal scutellar setae. Anatergite with tuft of short setulae. Anterior and posterior fringes of posterior spiracle unequal in size: posterior lappet distinctly larger. Legs. Preapical anterodorsal seta of fore tibia about as long as preapical dorsal seta. Mid tibia with one anterodorsal seta. Hind tibia with three preapical dorsal setae. Preapical posteroventral seta of hind tibia about as long as preapical anteroventral seta. Hind tibia with two well-developed anterodorsal setae. Posterodorsal margin of hind coxa bare. Wing (Figure 4A). Second costal section $\left(\mathrm{CS}_{2}\right)$ bare ventrally. Costal spine not differentiated from other costal setulae. Vein $\mathrm{R}_{1}$ bare. Base of vein $R_{4+5}$ with $2-4$ setulae dorsally and ventrally. Bend of vein $M$ forming obtuse angle. Fourth costal section $\left(\mathrm{CS}_{4}\right)$ longer than sixth $\left(\mathrm{CS}_{6}\right)$. Section of $\mathrm{M}$ between crossveins $\mathrm{r}-\mathrm{m}$ and $\mathrm{dm}-\mathrm{m} 1.1-1.2 \times$ longer than section between $\mathrm{dm}-\mathrm{m}$ and bend of vein $\mathrm{M}$. Cell $\mathrm{r}_{4+5}$ open.

Abdomen (Figure 4A). Mid-dorsal depression of syntergite $1+2$ confined to anterior 1/3 of syntergite. Syntergite $1+2$ without median marginal setae. Tergite 3 without median marginal and lateral discal setae, with two or three pairs of lateral marginal setae. Tergites 4 and 5 each with row of short marginal setae and without discal setae. Tergite 5 short, approximately $1.3 \times$ as long as tergite 4. Sternite 4 exposed. Terminalia (Figure 5). Sternite 5 with deep, wide, posteromedian notch with narrow membranous window. Transversal section of sternite 5 U-shaped. Tergite 6 well developed (i.e., plate-like) with median marginal setae. Connection between tergite 6 and syntergosternite 7 +8 membranous. Connection between sternite 6 and syntergosternite $7+8$ membranous on right side. Epandrium short and convex; anterior extension well developed, posterolateral lobe scarcely developed. Cerci normally developed, basally wide, not fused medially at base (i.e., suture between cerci complete and visible). Surstylus normally developed, basally wide, narrowing distally (distal third stick-like); setae on median extension present. Bacilliform sclerite and surstylus firmly fused. Connection between surstylus and epandrium membranous. Hypandrial arms converging medially, not fused. Connection between phallic guide and pregonite membranous (i.e., not fused). Anterior seta on postgonite present. Extensions of dorsal sclerite of distiphallus relatively short and partly fused medially to dorsal sclerite of basiphallus. Median process of ventral sclerotization of distiphallus present and not interrupted, running from ventral plate to tip of phallus. Median process of ventral sclerotization of distiphallus longitudinally not divided. Acrophallus simple (i.e., with one opening); lateral lobes of acrophallus with long (feather-like), sclerotized, hooked teeth, resembling a zipper. 
Female (Figure 6A-D) (4.5 mm). Generally darker in coloration, except wing membrane almost hyaline, differs from males as follows: outer vertical seta present, well developed; one pair of upper reclinate orbital setae; two pairs of proclinate orbital setae; frons approximately 3/4 of a compound eye in dorsal view. Terminalia (Figure 7A-C). Oviscapt moderately long and telescopic, retracted in fifth segment (Figure 7A). Segments 7 and 8 normally developed and unmodified. Tergite 8 rectangular and cerci normally developed, straight (Figure 7B,C). Three suboval spermathecae, dark brown in color (Figure 7A).

Distribution. Oriental: Vietnam (Cao Bang Province).

Biology. Unknown.

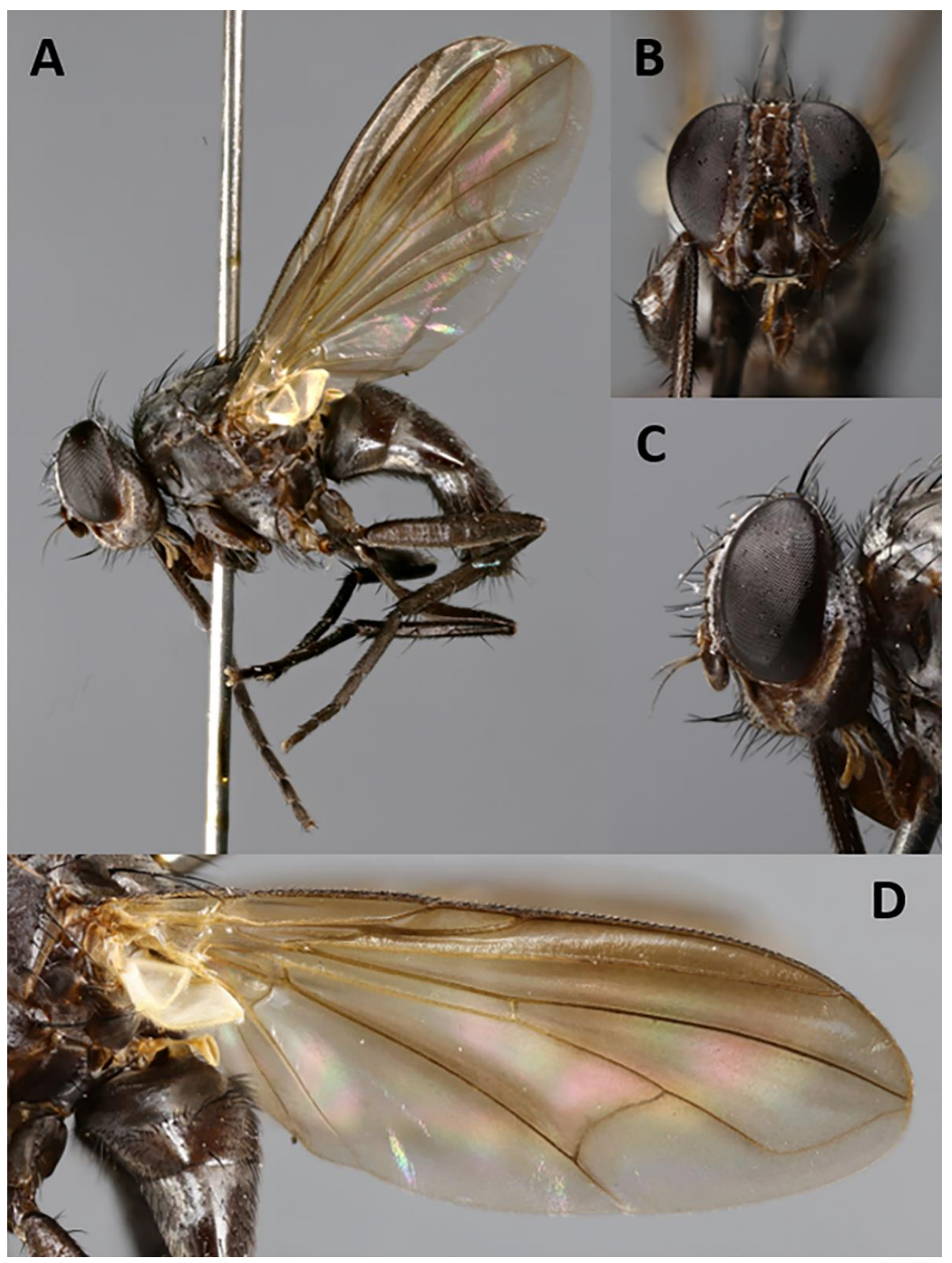

Figure 6. Baniassa pennata sp. nov. (paratype $\circ$, BLKU). (A) Habitus in lateral view; (B) head in frontal view; (C) head in lateral view; (D) left wing in ventral view. 

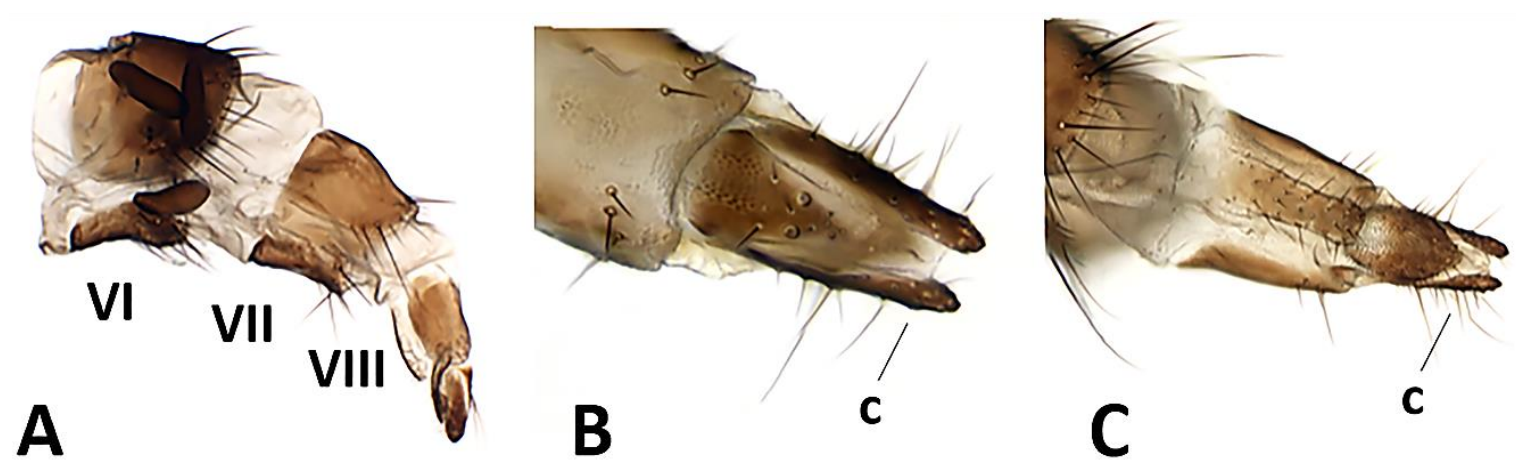

Figure 7. Baniassa pennata sp. nov., female terminalia (paratype + , CSCA). (A) Ovipositor in lateral view (showing segments VI, VII, VIII and three spermathecae); (B) distal tip of ovipositor in dorsal view, $\mathrm{c}=$ cercus; $(\mathbf{C})$ distal tip of ovipositor in ventral view, $\mathrm{c}=$ cercus.

Phyto Robineau-Desvoidy, 1830

Phyto Robineau-Desvoidy, 1830: 218 [original description]. Type species: Phyto nigra Robineau-Desvoidy, 1830 (=Tachina melanocephala Meigen, 1824), by designation of Townsend (1916:8).

References: [25-31].

Diagnosis. Afrotropical species of Phyto likely represent a monophyletic group characterized by a distinctive color pattern with contrasting black and silvery grey microtomentose bands (reminiscent of that of the tachinid genus Trigonospila Pokorny [32]). Lunule with setae. Parafacial bare. First postsutural supra-alar seta present and well developed, longer than notopleural setae. Male: frons very narrow (narrower than width of postpedicel); fronto-orbital plate without proclinate orbital setae.

Apomorphies. None. The present analyses retrieved Phyto as a paraphyletic grade from which the ancestor of Parazamimus and Baniassa arose. The clade composed of Phyto, Parazamimus and Baniassa is supported by a single local apomorphy (lunule with setae). See further under Discussion below.

Phyto mambilla sp. nov.

http://www.zoobank.org/A1AEBA3F-EBD6-4E8E-BB1C-A6304E9DB56D (Figures 8 and 9)

Type material. HOLOTYPE $\sigma^{7}$ : Nigeria, Gashaka-Gumti National Park. Label data: “Overgrown/cocoyam/plots in/village//Nigeria:/Mambilla/Plateau/Ngel Nyakl./28.xi.-3.xii.1968./J.C. Deeming." (CNC).

Etymology. The specific epithet, which should be treated as a noun in apposition, refers to the type locality.

Diagnosis. Male arista with long microtrichia (at most twice the maximum diameter of arista). Parafacial bare in ventral half. Postpronotum with two setae. Bend of vein $\mathrm{M}$ not reaching vein $\mathrm{R}_{4+5}$ so that cell $r_{4+5}$ is open at wing margin. Katepimeron with few hair-like setulae. 


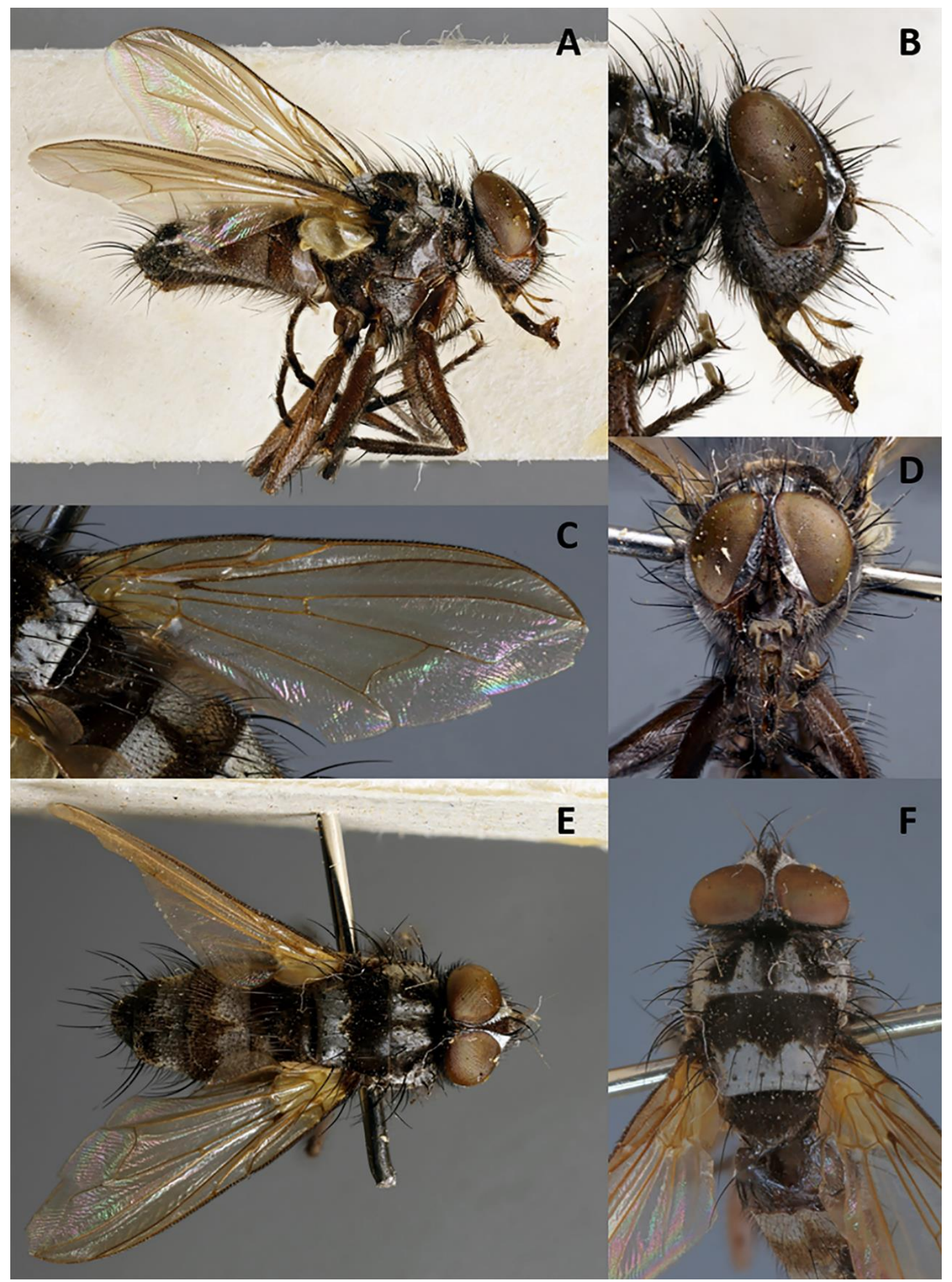

Figure 8. Phyto mambilla sp. nov. (holotype $\sigma^{7}, \mathrm{CNC}$ ). (A) Habitus in lateral view; (B) head in lateral view; (C) right wing in dorsal view; (D) head in frontal view; (E) dorsal habitus; (F) thorax in dorsal view. 
A

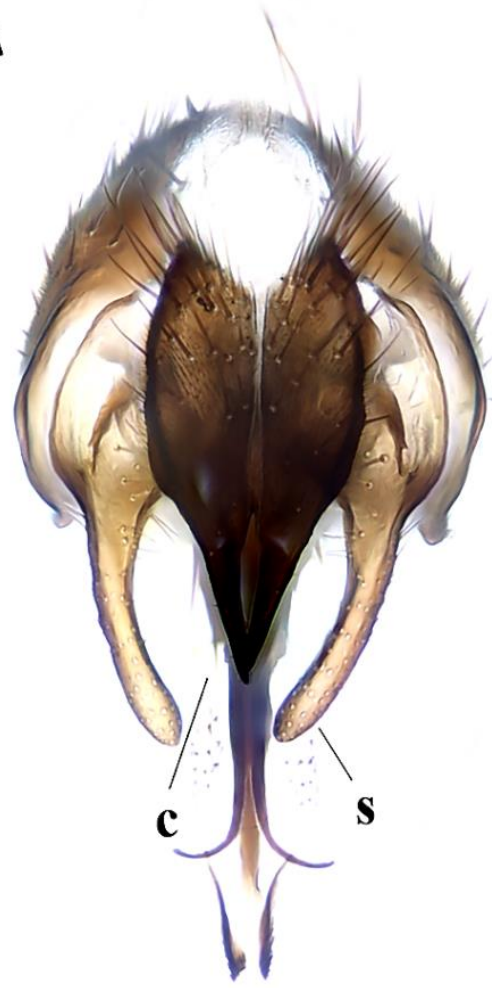

B

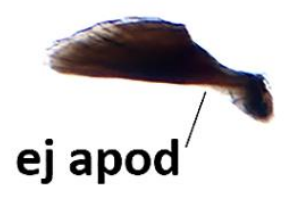

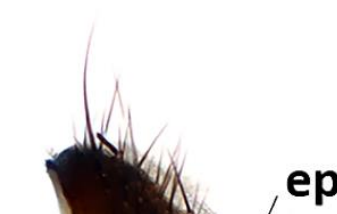

phapod

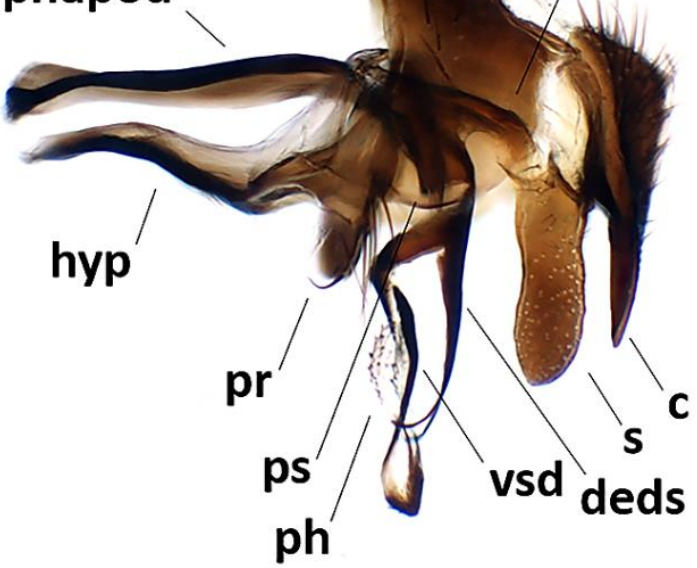

Figure 9. Phyto mambilla sp. nov., male terminalia (holotype $\sigma^{7}, \mathrm{CNC}$ ). (A) Cerci and surstyli in posterior view, $\mathrm{c}=$ cercus, $\mathrm{s}=$ surstylus; $(\mathbf{B})$ terminalia, phapod $=$ phallapodeme, $\mathrm{c}=$ cercus, deds = dorsal extension of dorsal sclerite of distiphallus, ej apod = ejaculatory apodeme, ep = epiphallus, hyp = hypandrium, $\mathrm{ph}=$ phallus, $\mathrm{pr}=$ pregonite, $\mathrm{ps}=$ postgonite, $\mathrm{s}=$ surstylus, $\mathrm{vsd}=$ ventral sclerotization of distiphallus.

Description. Male (Figures 8 and 9).

Length: $4.3 \mathrm{~mm}$.

Color (Figure 8A-F). Head black in ground color and covered with silvery grey microtomentum; frontal vitta brownish; area between gena and parafacial brownish to orange; scape, pedicel and postpedicel dark brown; palpus orangish. Thorax black in ground color; postpronotum silvery grey microtomentose; prescutum with two broad silvery grey microtomentose vittae; anterior $3 / 5$ of scutum black and posterior $2 / 5$ silvery grey microtomentose; scutellum black; anepisternum and katepisternum silvery grey microtomentose, remaining pleura black. Legs light brown shading to dark brown tarsi. Upper and lower calypters whitish. Wing hyaline; tegula and basicosta brown; veins yellow. Halter whitish. Abdomen brown in ground color with two broad silver bands; syntergite $1+2$ with brown mid-dorsal depression and silver lateral and ventral parts; tergites 3-4 each with silver band on anterior half, almost divided by brown triangle in the middle; terminalia brown.

Head (Figure 8A,B,D-F). Frons at narrowest point much narrower than postpedicel, not more than twice as wide as anterior ocellus, 0.072 of head width and $0.15 \times$ as wide as compound eye in dorsal view. Outer vertical seta not differentiated. Ocellar setae well developed, proclinate. Frons with 11 frontal setae descending to upper margin of pedicel. Fronto-orbital plate with few scattered hair-like setulae and frontal vitta obliterated at narrowest point. Upper reclinate orbital setae not differentiated from frontal row. Proclinate orbital setae absent. Parafacial bare, approximately as wide as postpedicel at mid length and well visible in profile. Facial ridge concave with setae above vibrissa on lower 1/5. Vibrissa inserted at level of lower facial margin. Face and lower facial margin not visible in lateral view. Gena approximately 0.3 of compound eye height. Genal dilation well developed. Lunula with setae. Antenna long, 3/4 of height of gena. Postpedicel 2.8-3.0 $\times$ as long as pedicel. Arista thickened on proximal $1 / 8$, with dorsal and ventral row of fine trichia equally long on upper and lower 
surfaces, at most $2.5 \times$ maximum basal diameter of arista and longest trichia longer than width of frons at narrowest point. First aristomere very short, much shorter than wide; second aristomere not longer than wide. Prementum about twice as long as width at mid length. Palpus apically enlarged.

Thorax. Postpronotum with two setae (Figure 8A,E,F). Two presutural and three postsutural acrostichal setae. Two presutural and three postsutural dorsocentral setae. Three postsutural intra-alar setae. First postsutural supra-alar seta well developed. Two + one katepisternal setae. Katepimeron with few hair-like setulae. Anepimeron with several hair-like setulae. One pair of apical scutellar setae, crossed. One pair of lateral scutellar setae. Anatergite bare. Anterior and posterior fringes of posterior spiracle equal in size, standing out from spiracular rim. Postmetacoxal area membranous. Legs. Preapical anterodorsal seta of fore tibia about as long as preapical dorsal seta. Mid tibia with one anterodorsal seta. Hind tibia with three preapical dorsal setae. Preapical posteroventral seta of hind tibia about as long as preapical anteroventral one. Hind tibia with two well-developed anterodorsal setae. Posterodorsal margin of coxa bare. Wing (Figure $8 \mathrm{C}$ ). Second costal section $\left(\mathrm{CS}_{2}\right)$ bare ventrally. Costal spine short but differentiated from other costal setulae. Vein $\mathrm{R}_{1}$ bare. Base of vein $\mathrm{R}_{4+5}$ with $3-4$ setulae dorsally and ventrally. Bend of vein $\mathrm{M}$ forming obtuse angle. Fourth costal section $\left(\mathrm{CS}_{4}\right)$ longer than sixth $\left(\mathrm{CS}_{6}\right)$. Section of $\mathrm{M}$ between crossveins $\mathrm{r}-\mathrm{m}$ and $\mathrm{dm}-\mathrm{m} 1.3 \times$ longer than section between $\mathrm{dm}-\mathrm{m}$ and bend of vein $\mathrm{M}$. Cell $\mathrm{r}_{4+5}$ closed at wing margin.

Abdomen (Figure 8A,E). Mid-dorsal depression of syntergite $1+2$ confined to anterior 2/3 of syntergite. Syntergite $1+2$ without median marginal setae, with one pair of lateral setae. Tergite 3 and 4 with short and recumbent dorsal setulae. Tergite 3 with one pair of median marginal and one pair of median discal setae, and three pairs of lateral marginal setae. Tergites 4 and 5 each with row of marginal setae and without discal setae. Tergite 5 short, approximately $1.4 \times$ as long as tergite 4 . Sternite 4 exposed. Terminalia (Figure 9A,B). Sternite 5 with deep posteromedian notch with sub-basal membranous window. Transversal section of sternite 5 U-shaped. Tergite 6 normally developed (i.e., plate-like) with median marginal setae. Connection between tergite 6 and syntergosternite $7+8$ membranous. Connection between sternite 6 and syntergosternite $7+8$ membranous on right side. Epandrium short and convex. Cerci normally developed, not fused medially at base (i.e., suture between cerci complete and visible). Surstylus normally developed, not divided; bifid inner median extension of surstylus absent. Bacilliform sclerite and surstylus articulated and not fused. Connection between surstylus and epandrium membranous. Hypandrial arms converging medially, not fused. Connection between phallic guide and pregonite membranous (i.e., not fused). Anterior seta on postgonite present. Extensions of dorsal sclerite of distiphallus divided into two hemisclerites. Median process of ventral sclerotization of distiphallus present, interrupted proximally and not connected to ventral plate. Median process of ventral sclerotization of distiphallus longitudinally not divided. Acrophallus simple (i.e., with one opening).

Female. Unknown.

Distribution. Afrotropical: Nigeria.

Biology. Unknown.

Key to the Afrotropical species of Phyto Robineau-Desvoidy (modified from Crosskey [29])

1. Postsutural area of scutum brownish black. Presutural area of scutum black with two narrow silvery grey microtomentose vittae (vittae laying between rows of acrostichal and dorsocentral setae and separated by black median vitta). Frons at narrowest point $0.080 \times$ as wide as head in dorsal view; frontal vitta not obliterated. Parafacial narrow and only just visible on lower half in profile. Two postsutural intra-alar setae, anterior seta closer to suture than to hindmost seta. Two postpronotal setae. Two katepisternal setae.

Phyto parafacialis Crosskey, 1977 (South Africa)

- Postsutural area of scutum with following color pattern: posterior third or two-fifths thickly pale yellowish or silver microtomentose (pale microtomentose areas strongly 
contrasting with black sublateral areas of presutural area and anterior part of postsutural area of scutum). Presutural area either with single wide yellowish microtomentose vitta medially or with two wide subtriangular vittae of silver microtomentum (vittae laying approximately along row of dorsocentral presutural setae); lateral black areas of presutural scutum not reaching transverse suture due to a rim of microtomentum. Frons at narrowest point at most $0.075 \times$ as wide as head in dorsal view; frontal vitta obliterated at narrowest point. Parafacial well visible in profile. Usually three postsutural intra-alar setae, median seta (or anterior one if only two present) as close to or closer to hindmost seta than to transverse suture. Two or three postpronotal setae; if three, then arranged in triangle. Three katepisternal setae.

2 (East and West Africa)

2. Presutural portion of scutum with two wide, subtriangular vittae of silver microtomentum (vittae laying approximately along row of dorsocentral presutural setae), separated by black median vitta; lateral black portions of presutural scutum broadly subtriangular in shape and not reaching transverse suture due to a rim of microtomentum. Frons at narrowest point 0.072 of head width.

Phyto mambilla sp. nov. (West Africa)

- Presutural portMedian third of presutural portion and hind margin of scutum thickly pale yellow microtomentose. Frons, at narrowest point, at most 0.065 of head width.

3 (East Africa)

3. Trichia on arista equally long on upper and lower surfaces; longest trichia longer than width of frons at narrowest point. Head ground color entirely blackish, subparafacial area (i.e., portion between genal grove, genal dilation and vibrissal triangle) and frontal vitta area velvety black (not paler than rest of head). Abdominal tergites 3 and 4 with dark color extending forwards as elongate blackish brown triangle on each tergite with apex at anterior margin (separating pale microtomentose basal parts of tergites into two). Dorsal setulae of abdominal tergites 3 and 4 very long, fine and erect. Frons at narrowest point much narrower than postpedicel, not more than twice as wide as anterior ocellus $(0.055 \times$ head width).

Phyto paratachinoides Crosskey, 1977

- Trichia on arista not as long on lower surface as upper surface and longest trichia shorter than width of frons at narrowest point. Head not entirely black; subparafacial area and frontal vitta orange-red, brick-red or reddish brown (i.e., paler than rest of head). Abdominal tergites 3 and 4 with dark areas slightly triangular but not extending forwards in mid line to anterior margins of tergites (bases of tergites therefore with uninterrupted broad pale microtomentose fasciae). Dorsal setulae of abdominal tergites 3 and 4 short and recumbent or virtually so. Frons at narrowest point only slightly narrower than postpedicel, conspicuously more than twice as wide as anterior ocellus (0.065× head width).

Phyto tachinoides (Curran, 1927) [33]

\section{Discussion and Conclusions}

Aporeomyia is an Oriental genus characterized by a tripartite postpedicel in males. In our analyses, Aporeomyia elaphocera sp. nov. clusters with Aporeomyia antennalis Pape \& Shima, and the genus is retrieved as sister to Kinabalumyia pinax Cerretti \& Pape within an Australasian/Oriental clade. Despite the fact that no female specimens of either species have been found to date, the peculiar antennal 
morphology likely represents a sexually dimorphic character [20]. Moreover, the discovery of a second species of Aporeomyia has given the opportunity to define this genus based on cladistic arguments as detailed above, and the marked difference in postpedicellar morphology between Aporeomyia and Kinabalumyia is considered here as further support for generic separation.

Baniassa pennata sp. nov. and Phyto mambilla sp. nov. cluster within a weakly supported Palaearctic/Afrotropical clade.

Baniassa is a Saharo-Arabian/Oriental genus, formerly known from only three species restricted in distribution to the Middle East, all of which shared a petiolate wing cell $\mathrm{r}_{4+5}$. Baniassa pennata sp. nov. has the wing cell $r_{4+5}$ open, thus presenting the plesiomorphic condition for this character; moreover, this new species remarkably broadens the genus concept and expands the distributional range to include the Oriental Region [34]. However, we are fully aware that the monophyly of Baniassa relies on four weak local apomorphies and that molecular data are needed to better circumscribe the genus.

With 26 described species, the genus Phyto, as it is currently defined, is the second most species-rich genus within Rhinophoridae: only Stevenia Robineau-Desvoidy comprises more species (28) [11]. Phyto mostly shows a west-Palaearctic distribution with only four species in the Afrotropical Region, all endemic: Phyto mambilla sp. nov., P. parafacialis Crosskey, P. paratachinoides Crosskey and P. tachinoides (Curran). According to our phylogeny, the phylogenetic position of Phyto mambilla sp. nov. renders Phyto paraphyletic with regard to Baniassa. Despite this result, we opted for a conservative classification, avoiding both the erection of a new genus to accommodate Phyto mambilla sp. nov. as well as the lumping of Phyto, Baniassa and Parazamimus into a single genus, because we consider such action premature, awaiting the imminent results from a comprehensive phylogeny of the Rhinophoridae based on molecular data (Gisondi et al., in prep.). Except for the remarkably different coloration pattern, characterized by white reflecting microtomentum contrasting with the dark integument, the Afrotropical species of Phyto are very similar to their Palaearctic congeners. Moreover, the two included Palaearctic species of Phyto provide insufficient coverage of the morphological diversity of the genus, and an improved taxon sampling is needed to resolve relationships in this group.

Supplementary Materials: The following are available online at http://www.mdpi.com/2075-4450/11/11/792/s1, Matrix S1: Morphological data matrix from Cerretti et al. [11,14] modified to include Aporeomyia elaphocera sp. nov. Baniassa pennata sp. nov. and Phyto mambilla sp. nov.

Author Contributions: Conceptualization, S.G., T.P. and P.C.; methodology, S.G. and P.C.; validation, S.G., T.P., H.S. and P.C.; formal analysis, S.G. and P.C.; specimen curation, S.G., T.P., H.S. and P.C.; writing-original draft preparation, S.G.; writing-review and editing, S.G., T.P, H.S. and P.C.; supervision, T.P and P.C.; project administration, T.P. and P.C. All authors have read and agreed to the published version of the manuscript.

Funding: This research received no external funding.

Acknowledgments: The authors are grateful to Jim O'Hara (CNC, Ottawa, ON, Canada), Steve Gaimari and Martin Hauser (CDFA, Sacramento, CA, USA) for loan arrangements and to Giuseppe Lo Giudice (CUFA and LaNaBIT, Verona, Italy) for graphical assistance.

Conflicts of Interest: The authors declare no conflict of interest.

\section{References}

1. Thompson, W.R. The tachinid parasites of woodlice. Parasitology 1934, 26, 378-448. [CrossRef]

2. Bedding, R.A. Parasitism of British Terrestrial Isopoda by Diptera. Ph.D. Thesis, Imperial College of Science and Technology, London, UK, 1965; p. 234, Unpublished.

3. Bedding, R.A. The immature stages of Rhinophorinae (Diptera: Calliphoridae) that parasitise British woodlice. T. Roy. Ent. Soc. Lond. 1973, 125, 27-44. [CrossRef]

4. Sassaman, C.; Pratt, G. Melanophora roralis, a parasite of isopod crustaceans, in laboratory culture. Entomologist 1992, 111, 178-186.

5. Pape, T.; Arnaud, P.H., Jr. Bezzimyia-A genus of New World Rhinophoridae (Insecta, Diptera). Zool. Scr. 2001, 30, 257-297. [CrossRef] 
6. Wood, C.T.; Nihei, S.S.; Aurajo, P.B. Woodlice and their parasitoid flies: Revision of Isopoda (Crustacea, Oniscidea)-Rhinophoridae (Insecta, Diptera) interaction and first record of a parasitized Neotropical woodlouse species. Zookeys 2018, 801, 401-414. [CrossRef]

7. Kato, D.; Tachi, T. Revision of the Rhinophoridae (Diptera: Calyptratae) of Japan. Zootaxa 2016, 4158, 81-92. [CrossRef]

8. Lo Giudice, G.; Pape, T.; Cerretti, P. Revision of Malayia Malloch, with the first reports of Rhinophoridae from India and Indonesia (Diptera: Oestroidea). Fragm. Entomol. 2016, 48, 61. [CrossRef]

9. Nihei, S.S.; Andrade, M.R.; Pape, T.; Cerretti, P. The Shannoniella sisters (Diptera: Rhinophoridae). Zootaxa 2016, 4061, 85-92. [CrossRef]

10. Gisondi, S.; Lenzi, A.; Ziegler, J.; Di Giulio, A.; Cerretti, P. Stevenia gilasiani sp. nov. (Diptera: Rhinophoridae): The first woodlouse fly with male sexual-patches. Zootaxa 2019, 4571, 423-431. [CrossRef]

11. Cerretti, P.; Badano, D.; Gisondi, S.; Lo Giudice, G.; Pape, T. The world woodlouse flies (Diptera: Rhinophoridae). Zookeys 2020, 903, 1-130. [CrossRef]

12. Cumming, J.M.; Wood, D.M. Adult morphology and terminology. In Manual of Afrotropical Diptera; Kirk-Spriggs, A.H., Sinclair, B.J., Eds.; Suricata 4; South African National Biodiversity Institute: Pretoria, South Africa, 2017; Volume 1, pp. 89-133.

13. O'Hara, J.E. Revision of the Polideini (Tachinidae) of America north of Mexico. Stud. Dipterol. Suppl. 2002, 10, 1-170.

14. Cerretti, P.; Lo Giudice, G.; Pape, T. Remarkable Rhinophoridae in a growing generic genealogy (Diptera: Calyptratae, Oestroidea). Syst. Ent. 2014, 39, 660-690. [CrossRef]

15. Maddison, W.P.; Maddison, D.R. Mesquite: A Modular System for Evolutionary Analysis. 2015. version 3.03. Available online: http://mesquiteproject.org (accessed on 15 June 2020).

16. Goloboff, P.A.; Catalano, S.A. TNT version 1.5, including a full implementation of phylogenetic morphometrics. Cladistics 2016, 32, 221-238. [CrossRef]

17. Goloboff, P.A. Analyzing large data sets in reasonable times: Solution for composite optima. Cladistics 1999, 15, 415-428. [CrossRef]

18. Congreve, C.R.; Lamsdell, J.C. Implied weighting and its utility in palaeontological datasets: A study using modelled phylogenetic matrices. Palaeontology 2016, 59, 447-462. [CrossRef]

19. Verbeke, J. Contribution a l'étude des Tachinidae africains (Diptera). Exploration Hydrobiologique des Lacs Kivu, Édouard et Albert (1952-1954). Résultats Sci. 1962, 3, 77-187.

20. Pape, T.; Shima, H. A new genus of Tachinidae from the Phillippines (Diptera). Tijdschr. Entomol. 1993, 136, $77-81$.

21. Kugler, J. The Rhinophoridae (Diptera) of Israel. Isr. J. Entomol. 1978, 12, 65-106.

22. Pape, T. A new species of Baniassa Kugler from Iraq (Diptera: Rhinophoridae). Entomol. Scand. 1985, 16, 209-211. [CrossRef]

23. Pape, T. Family Rhinophoridae. In Contributions to a Manual of Palaearctic Diptera (with Special Reference to Flies of Economic Importance); Papp, L., Darvas, B., Eds.; Higher Brachycera; Science Herald: Budapest, Hungary, 1998; Volume 3, pp. 679-689.

24. Zeegers, T. Order Diptera, family Rhinophoridae. Arthropod Fauna UAE 2008, 1, 732-740.

25. Meigen, J.W. Systematische Beschreibung der Bekannten Europäischen Zweiflügeligen Insekten; Vierter Theil; Schulz-Wundermann: Hamm, Germany, 1824; p. XII + 428.

26. Robineau-Desvoidy, J.-B. Essai sur les myodaires. Mem. Math. Phys. Acad. Sci. Paris (Sér. 2) 1830, 2, 1-813.

27. Townsend, C.H.T. Designations of muscoid genotypes, with new genera and species. Insecutor Inscitiae Menstruus 1916, 4, 4-12.

28. Herting, B. 64e. Rhinophorinae. In Die Fliegen der Palaearktischen Region (Lieferung 216); Lindner, E., Ed.; E. Schweizerbart'sche Verlagsbuchhandlung: Stuttgart, Germany, 1961; pp. 1-36.

29. Crosskey, R.W. A review of the Rhinophoridae (Diptera) and a revision of the Afrotropical species. Bull. Br. Mus. Nat. His. Entomol. 1977, 36, 1-66.

30. Tschorsnig, H.P. Die Struktur des männlichen Postabdomens der Rhinophoridae (Diptera). Stutt. Beitr. Naturkd. A 1985, 375, 1-18.

31. Pape, T. A phylogenetic analysis of the woodlouse-flies (Diptera, Rhinophoridae). Tijdschr. Entomol. 1986, 129, 15-34.

32. Pokorny, E. Vier neue österreichische Dipteren. Wien. Entomol. Ztg. 1886, 5, 191-196. [CrossRef] 
33. Curran, C.H. Studies in African Tachinidae (Diptera)-II. B. Entomol. Res. 1927, 18, 103. [CrossRef]

34. Holt, B.G.; Lessard, J.-P.; Borregaard, K.; Fritz, S.A.; Araújo, M.B.; Dimitrov, D.; Fabre, P.-H.; Graham, C.H.; Graves, G.R.; Jønsson, K.A.; et al. An update of Wallace's zoogeographic regions of the world. Science 2013, 339, 74-78. [CrossRef]

Publisher's Note: MDPI stays neutral with regard to jurisdictional claims in published maps and institutional affiliations.

(C) 2020 by the authors. Licensee MDPI, Basel, Switzerland. This article is an open access article distributed under the terms and conditions of the Creative Commons Attribution (CC BY) license (http://creativecommons.org/licenses/by/4.0/). 